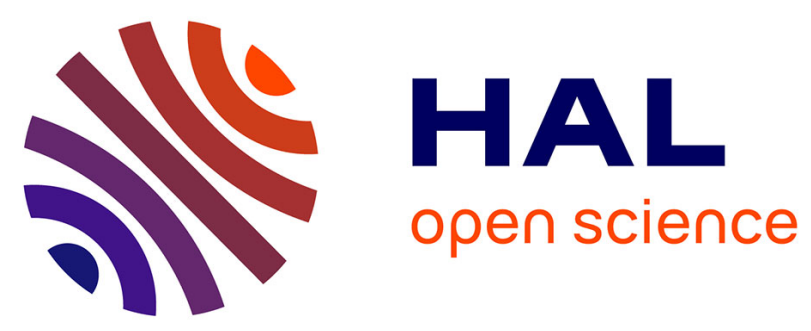

\title{
Calorimetric measurement and modelling of iron losses in a Silicon Iron current sensor
}

Hakim Dhahbi, Olivier Gallot-Lavallee, Afef Kedous-Lebouc, Patrick Mas, Olivier Geoffroy, Sebastien Buffat

\section{- To cite this version:}

Hakim Dhahbi, Olivier Gallot-Lavallee, Afef Kedous-Lebouc, Patrick Mas, Olivier Geoffroy, et al.. Calorimetric measurement and modelling of iron losses in a Silicon Iron current sensor. International Journal of Applied Electromagnetics and Mechanics, 2019, 59 (2), pp.473-482. 10.3233/JAE-171022 . hal-02350921

\section{HAL Id: hal-02350921 \\ https://hal.science/hal-02350921}

Submitted on 3 Dec 2020

HAL is a multi-disciplinary open access archive for the deposit and dissemination of scientific research documents, whether they are published or not. The documents may come from teaching and research institutions in France or abroad, or from public or private research centers.
L'archive ouverte pluridisciplinaire HAL, est destinée au dépôt et à la diffusion de documents scientifiques de niveau recherche, publiés ou non, émanant des établissements d'enseignement et de recherche français ou étrangers, des laboratoires publics ou privés. 


\title{
Calorimetric measurement and modelling of iron losses in a Silicon Iron current sensor
}

\author{
Hakim DHAHBI ${ }^{\mathrm{a}, \mathrm{b}}$, Olivier GALLOT-LAVALLEE ${ }^{\mathrm{a}}$, Afef KEDOUS-LEBOUC $^{\mathrm{a}}$, Patrick MAS ${ }^{\mathrm{b}}$, \\ Olivier GEOFFROY ${ }^{a}$ and Sebastien BUFFAT ${ }^{b}$ \\ ${ }^{a}$ Univ. Grenoble Alpes, CNRS, Grenoble INP, G2Elab \\ 38000 Grenoble, France \\ ${ }^{\mathrm{b}}$ Schneider Electric, F-38320 Eybens, France
}

\begin{abstract}
In this paper, the magnetic losses of a supply current sensor dedicated to circuit breakers are investigated. Measurements were performed using an accurate calorimeter covering a measurement range of $[1 \mathrm{~mW} ; 10 \mathrm{~W}]$. Several frequencies and voltages were tested. A model of the sensor's core material (NO SiFe sheet M250-50A) was built with the Loss Surface (LS) dynamic hysteresis model and implemented in a 3D FEM computation tool. The sensor was simulated and iron losses were computed. Comparison between experiments and simulation shows a high concordance that leads to conclude about the reliability of the LS model.
\end{abstract}

Keywords: Iron losses, current sensor, Silic on Iron magnetic steel, circuit breaker, modelling and experiment, Epstein bench.

\section{Introduction}

The continuous improvement of Schneider Electric's sensors requires a good knowledge of the device behaviour and a constant evolution of the design approach developed. This study focuses on the magnetic losses analysis and prediction in the power supply sensors installed in the Masterpact ${ }^{\circledR}$ circuit breakers. Simulations using 3D FEM tools are commonly used for the design of this sensor, but they require compatible materials models. In this study, the LS (Loss Surface) hysteresis model is integrated in the FLUX software and used in the post processing mode for the losses computation. To verify the relevance of this approach, a comparison with experiment on a real device is necessary. As the sensor geometry is complex, conventional electric measurements are not valid and a calorimetric method is performed.

\section{The Masterpact ${ }^{\circledR}$ NW current sensor}

Masterpact ${ }^{\circledR}$ circuit breakers are dedicated to low voltage high current distribution. The opening of these breakers relies on an electronic device allowing a large adaptability on current level rating and protection threshold. It gives also the possibility to integrate complex algorithms for the signal processing. This electronic device is designated by "Micrologic". For obvious security reasons the Micrologic needs to be supplied from the same network that the breaker secures. Knowing that the Micrologic can't stand power levels as high as those of the network it's compulsory to regulate the power levels fed to the Micrologic. This is ensured by the Masterpact ${ }^{\circledR}$ NW power supply current sensor [1] (Fig. 1) associated to a suitable power supply circuit (Fig. 2). The magnetic circuit of the Masterpact ${ }^{\circledR}$ sensor is manufactured using non-oriented silicon iron sheets M250-50A. It supplies the circuit through its secondary coil. This power supply sensor is associated to a Rogowski coil for the current measurements.

In case of an incident, the energy stored in the capacitor is released to insure the opening of the breaker. These current breakers are designed to operate from 80 A to 2000 A. Our study focuses on the sensor installed in high amperage breakers.

For our study we identify five main parts of the sensor (Fig. 1): (a) secondary coil branch, (b) flank, (c) flank shunt, (d) shunt and (e) ring. There is a functional $2 \mathrm{~mm}$ air gap between the shunt (d) and the flank (b). The shunt allows a part of the principal magnetic flux to be deviated at high current levels in order to limit the secondary current level in an acceptable range for the Micrologic. 


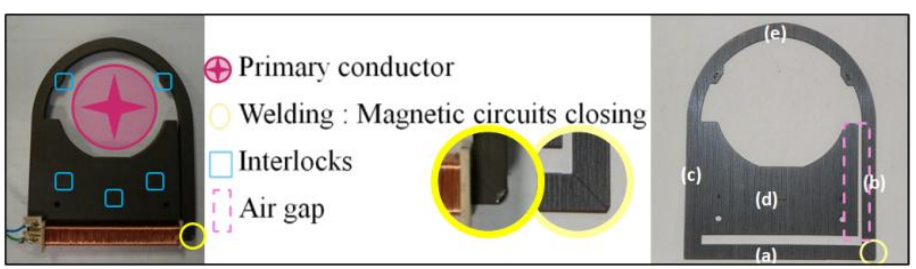

Fig. 1. Masterpact ${ }^{(B)} \mathrm{NW}$ current sensor

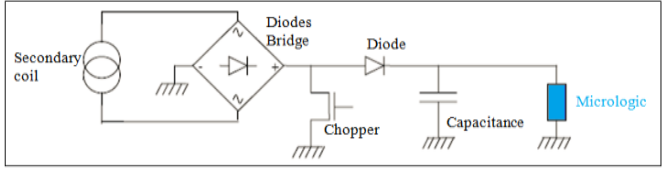

Fig. 2. Power supply circuit

The magnetic circuit is made from SiFe sheets punched in one piece, then stacked and assembled. Note that the angle between the induction and the lamination direction is variable (Fig. 3) conditioning the permeability and the reluctance of each area in the sensor. Otherwise, it's clear that the sensor parts have various widths, thus the residual stress impact on the magnetic properties is also different [2]. These characteristics lead to an inhomogeneous distribution of the induction and so the iron losses. The result is a various shape of the induction signal $\mathrm{B}(\mathrm{t})$ depending on the sensor area (Fig. 4). Then we can highlight that the SiFe sheets are interlocked (Fig. 1) and the secondary coil is added after the sheets assembly which causes a residual air gap. These manufacturing methods generate a bridge joining the $\mathrm{SiFe}$ sheets [3] that induces a circulation of eddy current among the whole sensor thickness which leads to important dynamic losses.

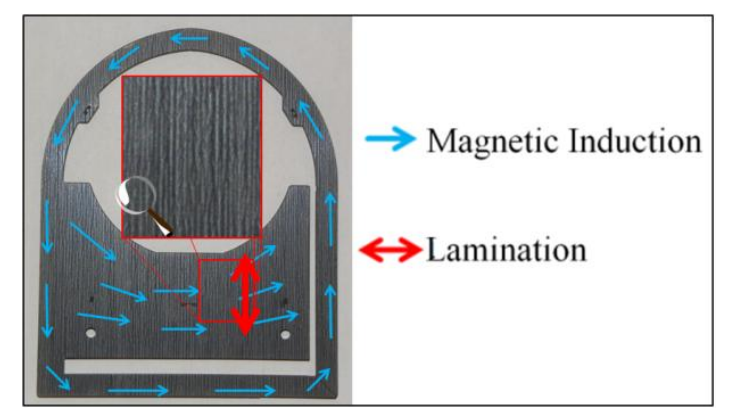

Fig. 3. Magnetic flux direction vs lamination direction in the sensor

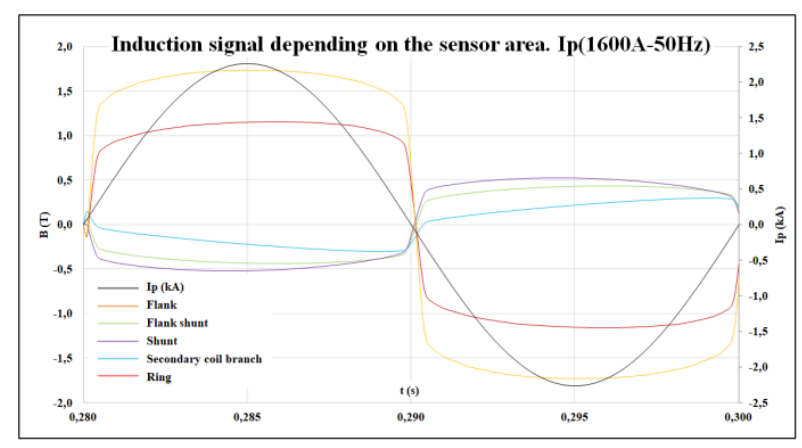

Fig. 4. Induction $\mathrm{B}(\mathrm{t})$ at $\mathrm{Ip}=\mathrm{Ip} \mathrm{p}_{\max }$ depending on sensor areas (simulated with secondary coil on short-circuit)

The modelling of the sensor using FLUX 3D, is realised assuming some simplifications on physical and design levels: isotropic material characterized by an average law $\mathrm{B}(\mathrm{H})$ measured on rolling and transverse directions of the sheet, no interlocks, no welding and no punching effects consideration. Otherwise, the secondary coil is short-circuited since the study focuses on high currents. Despite these simplifications, the simulations show consistent results in which we can observe the local induction (Fig. 5.a) and losses. These local losses result in a local overheating observed thanks to an IR thermography (Fig. 5.b).

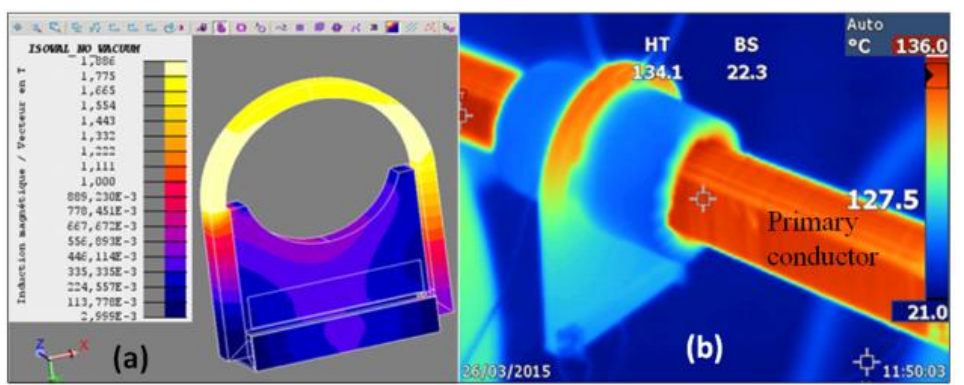

Fig. 5. Concordance between local induction (a) (simulations) and local overheat (b) (experiments) at Ip (2kA-400Hz)

All these characteristics highlight the complexity of the sensor behaviour and the difficulties of its iron losses prediction. That is why calorimetric experimentations are investigated to estimate the reliability of simulations. 


\section{Iron losses measurements}

\subsection{Calorimetric bench}

Developed at G2Elab, the calorimeter $[4,5,6]$ used in this experiment is primarily devoted to characterize power electronic components up to $3 \mathrm{kV}$ and $1 \mathrm{MHz}$ and within the temperature range of 50 to $+150{ }^{\circ} \mathrm{C}$. It is based on radiation energy transfer and uses a suitable vacuum enclosure (Fig. 6) which contains the heater and all temperature sensors. In order to insure a stable temperature reference the measurements cell is linked to a liquid Nitrogen container representing a heat well. The bridge is a bar made of a material chosen according to the measured temperature range. Moreover, given that a perfect isolation is impossible, a differential measurement method is adopted (Fig. 7). The cell is maintained at a fixed temperature $T_{0}$ without supplying the sensor (No load operation). The power needed for this task is $P_{0}$. Then we supply the sensor while maintaining the cell at the same temperature $T_{0}$. The sensor losses $P_{s}$ are added to the balance so that the calorimeter supply is reduced to $P_{1}<P_{0}$ where $P_{s}=P_{0}-P_{1}$. In these conditions the calorimeter offers a measurement range from $1 \mathrm{~mW}$ to $10 \mathrm{~W}$ with an accuracy of $2 \%$ at $100 \mathrm{~mW}$.

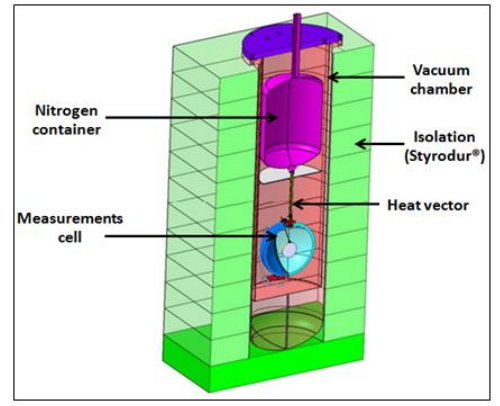

Fig. 6. The calorimeter design

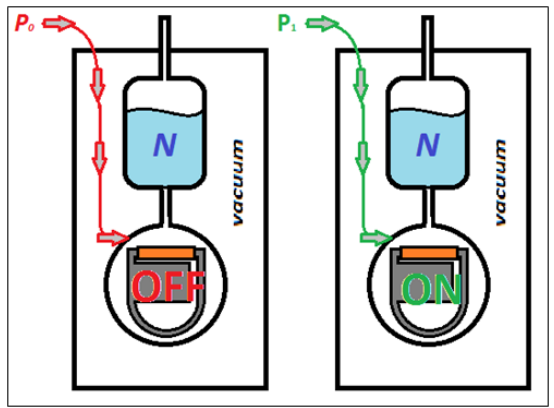

Fig. 7. Differential measurement method

Measurements and power supply instruments for the sensor are outside the enclosure. In order to insure thermal isolation, vacuum stability and good electrical connections, technical conditions on electrical cables and connectors are very strict. As a result, the material used to insure all these conditions limits the current supply to $1 \mathrm{~A}$.

\subsection{Calorimetric experimentations}

The calorimeter, was designed for small electrical components and has never been used for a complex device as the sensor Masterpact ${ }^{\circledR}$ NW. So it doesn't present the optimal condition for our application. Indeed, the current limit to $1 \mathrm{~A}$ is significantly lower than sensor practical operating current. As a solution, we decided to supply the sensor from its secondary coil (Fig. 8). The voltage across the secondary coil is linked to the main flux in the sensor by the equation (1). As $I_{\operatorname{mag}}$ is low in the case studied, we could link induction with voltage and frequency.

$$
V=N \cdot d \emptyset / d t+R \cdot I_{\text {mag }}
$$

Where $\mathrm{N}$ is the number of turns of the secondary coil, $\mathrm{R}$ the measured coil resistance and $\mathrm{I}_{\mathrm{mag}}$ the current.

We decided to control the sensor power supply voltage because of the particular configuration in the calorimeter. We injected various sinusoidal voltages: 10, 20, 30 and $40 \mathrm{~V}$ at various frequencies: 50, $100,150,200,300$ and $400 \mathrm{~Hz}$. Then we measured the corresponding losses. The sensor losses $P_{s}$ are the sum of the iron losses $P_{F e}$ and the copper Joule losses $P_{C u}$. Yet the coil and supply characteristics are known so are the Joule losses. Then we can deduce the iron losses (Eq. (2)). Except for the test $50 \mathrm{~Hz} 40$ $\mathrm{V}$, the copper losses are negligible so the measured sensor losses are mostly the iron losses contribution. Errors on $P_{C u}$ measures are barely noticed $\left(\varepsilon_{\mathrm{Cu}}<2 \%\right)$.

$$
P_{F e}=P_{s}-P_{C u}
$$

The main constraint of this experimentation was time: $48 \mathrm{~h}$ to $72 \mathrm{~h}$ for the installation of the calorimeter and $4 \mathrm{~h}$ to $6 \mathrm{~h}$ for each measured point. Add to that the installation of the sensor in the measurements cell was laborious given the close dimensions of both and the necessity to insure absolute absence of any contact between cell walls and the sensor. 


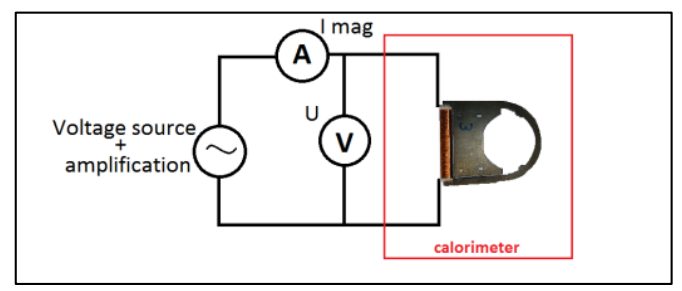

Fig. 8. Power supply of the sensor in the calorimeter

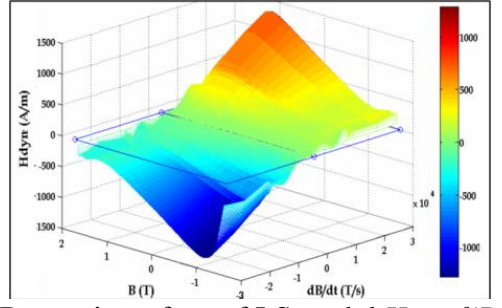

Fig. 9. Dynamic surface of LS model $H_{d y n}=f(B, d B / d t)$

Also the establishment of the secondary vacuum in the chamber needs time. Finally, the refill of the nitrogen container influences the energy balance inside the calorimeter and induces longer stabilization time for the measure in progress.

\section{Iron losses modeling}

\subsection{LS model}

The LS model is one of the models [7] studied for this work. Implemented in the software FLUX (Altair - France), this model [8,9] is a scalar model of global hysteresis including both static and dynamic behaviour. It links the magnetic field $H$ to the induction $B$ and its derivative $d B / d t$. In FLUX the LS model is applied as post-possessing. In these conditions we neglect the influence of the losses and hysteresis on the modelled system. The simulation is realized with FEM based on a bijective $H(B)$ curve. The losses are estimated afterwards, after the reconstruction of the hysteresis cycle by calculating $H$ for each couple $(B, d B / d t)$ obtained in each element.

In the LS model the magnetic field $H$ is split into two contributions: static and dynamic identifiable independently (Eq. (3)). The static field is likewise split into two parts: the anhysteretic component $H_{a n h}$ and the irreversible one $H_{\text {irr }}$ (Eq. (4)). The latter depends on the material history. The dynamic field is expressed by a polynomial formula (Eq. (5)) which parameters are obtained during the identification of the model. This interpolation gives the specific surface of the LS model (Fig. 9).

$$
\begin{aligned}
& H\left(B, \frac{d B}{d t}\right)=H_{\text {stat }}(B, \text { history })+H_{\text {dyn }}\left(B, \frac{d B}{d t}\right) \\
& H_{\text {stat }}(B, \text { history })=H_{\text {anh }}(B)+H_{\text {irr }}(B) \\
& H_{d y n}\left(B, \frac{d B}{d t}\right)=\sum_{(n, m)} \alpha_{n m} B^{n}\left(\frac{d B}{d t}\right)^{m}
\end{aligned}
$$

The model is based on measurements achieved on an Epstein bench [10]. Its parameters are identified thanks to experimental cycles carried out under an imposed triangular induction $B(t)$ so that its derivative is kept constant $\left(d B / d t= \pm 4 . f . B_{\max }\right.$ where $f$ is the frequency). These parameters permit the reconstruction of the magnetic field for any $(B, d B / d t)$ couple. The M250-50A model has been identified and added to the LS materials bank.

The LS static model parameters are identified using quasi-static cycles considering in our case a frequency of $10 \mathrm{~Hz}$ : a major cycle measured at the highest induction permitted by the experimental bench called $B_{s a t}$ and few minor centered cycles obtained at lower inductions. The $H_{a n h}(B)$ is obtained from the major cycle by averaging the field of the rising branch and the decreasing branch. The $H_{\text {irr }}(B)$ is built using reversal curves obtained by the model parameters.

The LS dynamic model parameters are identified using a set of about 20 hysteretic loops at the same induction $B_{\text {sat }}$ as the major cycle but at different frequencies, e.g. from $10 \mathrm{~Hz}$ to $2 \mathrm{kHz}$. The parameters $\alpha_{n m}$ are obtained by interpolating experimental data in order to fit the equation (3).

After the parameters identification, the magnetic field is reconstructed via Eq. (1). Verifications were performed as shown in Fig. 10 in order to evaluate the consistence of the model before implementation in FEM simulation tool.

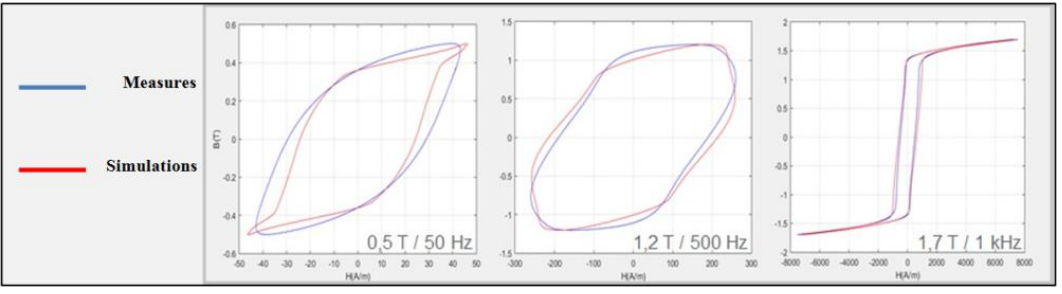

Fig. 10. Example of LS model verification: M250-50A, Sine $50 \mathrm{~Hz}$ 


\subsection{FLUX 3D simulations and LS losses prediction}

To reproduce the calorimeter experiments, the LS model of the M250-50A material was implemented in FLUX 3D software and simulations have been performed in the same conditions as measurements. Figure 11 shows an example of induction distribution and highlights that the levels are lower than normal operation.

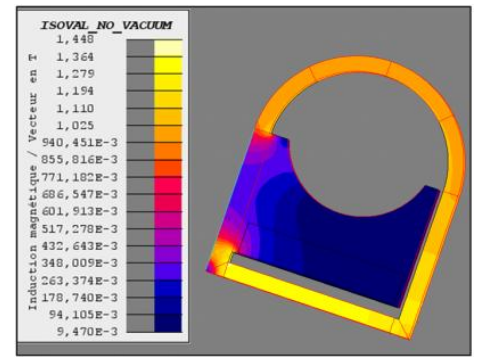

Fig. 11. Induction le vels at $40 \mathrm{~V} / 50 \mathrm{~Hz}$ (secondary coil supply)

\section{Results and discussions}

As previously mentioned, the main studied parameters are voltage and frequency. Both simulations and measures have been based on these parameters. In the measured power range and with a temperature $T_{0}=30^{\circ} \mathrm{C}$ the highest error on measured power is $1.5 \%$ [6, p.152]. Our goal is the comparison between LS (simulated) losses and measured losses.

\subsection{Iron losses versus voltage at a same frequency}

Table 1. Comparison at same frequency for different voltages Masterpact ${ }^{\circledR}$ NW (Measures VS LS)

\begin{tabular}{ccccccc}
$\boldsymbol{U}(\boldsymbol{V})$ & $\boldsymbol{f}(\mathrm{Hz})$ & $\begin{array}{c}\text { Coil Losses } \\
(\% \text { of all losses })\end{array}$ & $\begin{array}{c}\text { Measured Losses } \\
\mathbf{M 2 5 0 - 5 0 A}(\mathbf{m} \boldsymbol{W})\end{array}$ & $\begin{array}{c}\text { Losses LS } \\
\mathbf{M 2 5 0 - 5 0 A}(\mathbf{m W})\end{array}$ & $\begin{array}{c}\text { Discrepancy } \\
(\boldsymbol{\%})\end{array}$ & $\|\boldsymbol{B}\|_{\max }(\boldsymbol{T})$ \\
\hline 10 & 50.5 & 7.3 & 24 & 16 & -33.3 & 0.37 \\
\hline 20 & 50 & 7.2 & 83 & 73 & -12 & 0.73 \\
\hline 30 & 50 & 13.3 & 134 & 298 & 12.7 & 1.04 \\
\hline 40 & 50.5 & 52.5 & 281 & 6 & 1.2 \\
\hline
\end{tabular}

Induction levels are lower than $1.2 \mathrm{~T}$ which indicates that induction signals in the sensor are still sine waves forasmuch the magnetic behavior is still linear for these levels. Some frequency values have been changed to $50.5 \mathrm{~Hz}$ in order to avoid instrumental resonance with the electrical network.

Except for the $40 \mathrm{~V} / 50 \mathrm{~Hz}$ case, coil losses are effectively weak. The curves in Fig. 12 show a high concordance between measured losses and LS model results.

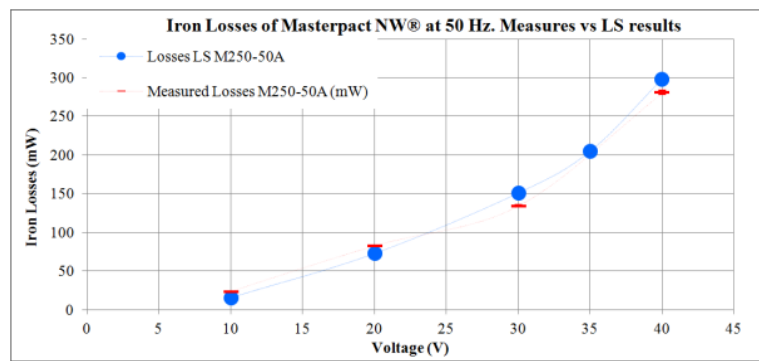

Fig. 12. Calorimetric results vs LS simulations on iron losses of the Masterpact ${ }^{(B)} \mathrm{NW}$ at $50 \mathrm{~Hz}$

\subsection{Iron losses versus frequency at a same voltage}

Table 2. Comparison at same voltage for different frequencies Masterpact ${ }^{\oplus} \mathrm{NW}$ (Measures vs LS)

\begin{tabular}{|c|c|c|c|c|c|c|}
\hline$U(V)$ & $f(H z)$ & $\begin{array}{c}\text { Coil Losses } \\
\text { (\% of all losses) }\end{array}$ & $\begin{array}{l}\text { Measured Losses } \\
\text { M250-50A }(\mathrm{mW})\end{array}$ & $\begin{array}{c}\text { Losses LS } \\
\text { M250-50A (mW) }\end{array}$ & $\begin{array}{c}\text { Discrepancy } \\
(\%)\end{array}$ & $\|\boldsymbol{B}\|_{\max }(\boldsymbol{T})$ \\
\hline 40 & 50.5 & 52.5 & 281 & 298 & 6 & 1.2 \\
\hline 40 & 100 & 3.6 & 194 & 200 & 3.25 & 0.704 \\
\hline 40 & 150 & 2.3 & 176 & 166 & -5.6 & 0.48 \\
\hline 40 & 200 & 1.75 & 170 & 147 & -13.5 & 0.38 \\
\hline 40 & 300 & 1.73 & 115 & 132 & -14.8 & 0.26 \\
\hline 40 & 400 & 1.3 & 115.5 & 138 & -19.5 & 0.2 \\
\hline
\end{tabular}


In this case more results are available so that the analysis is more precise and developed (Table 2). The same observations as for Table 1 can be done.

Working at a constant voltage and an increasing frequency leads to the decrease of the induction level and explains why the iron losses decrease (Fig. 12). However, this observation is true for $f \leq 300 \mathrm{~Hz}$. Indeed, iron losses start to increase when the frequency becomes higher than $300 \mathrm{~Hz}$ as the cycle surface increases (Fig. 12). This result is explained by a more important contribution of eddy current in the dynamic losses at high frequency.

In this comparison, the consistence of simulated and measured losses behavior is more obvious as slope variations are in concordance (Fig. 14).

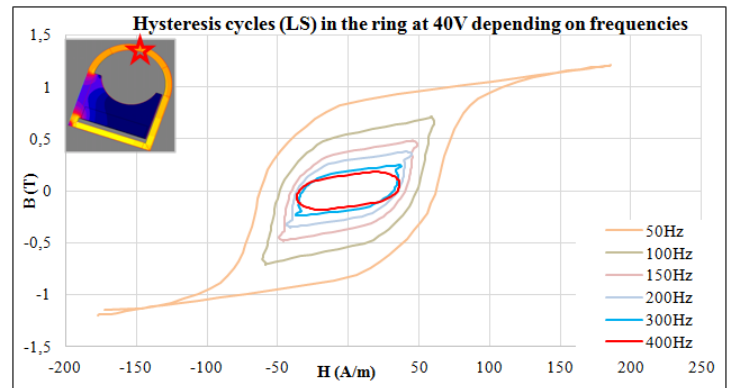

Fig. 13. LS hysteretic loops of the Masterpact ${ }^{(B)} \mathrm{NW}$ at $40 \mathrm{~V}$ depending on frequencies

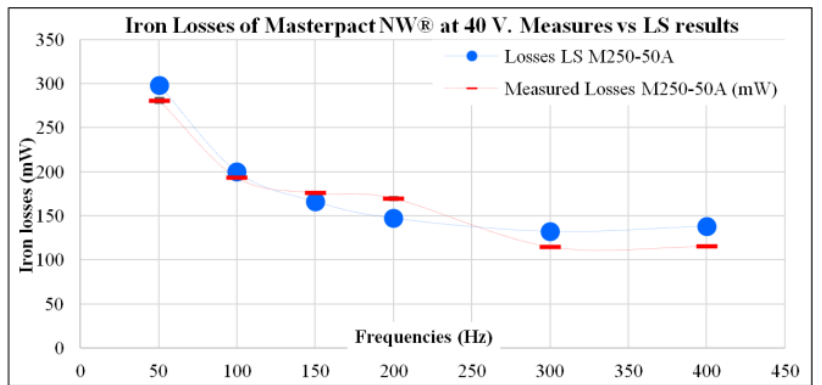

Fig. 14. Calorimetric results VS LS simulations on iron losses of the Masterpact ${ }^{\circledR} \mathrm{NW}$ at same voltage

\section{Conclusions}

This work highlighted many conclusions about the calorimeter, the sensors behaviour, the consistence of the LS model as well as the simulations and measurements of the Masterpact ${ }^{\circledR} \mathrm{NW}$.

The LS model shows satisfactory results. It describes accurately the Masterpact ${ }^{\circledR}$ NW behaviour with acceptable errors on most cases. This justifies all the energy and time devoted to the development of the LS model. In addition, this study was a first validation of the M250-50A LS model on real case. It also shows the weaknesses of the model at low inductions $(B \leq 0.3 T)$ and low frequencies $(f \leq 50 \mathrm{~Hz})$. We are currently working on improving the accuracy and reliability of the LS model.

This work permitted the iron losses estimations on the Masterpact ${ }^{\circledR} \mathrm{NW}$ in a different configuration from its devoted one. It was a relevant experimentation so a new calorimeter more suitable to test the Masterpact ${ }^{\circledR} \mathrm{NW}$ sensor in real functioning conditions was designed and is under tests. The preliminary results are promising.

Finally, it was an interesting test of the calorimeter out of its normal use which highlighted its capabilities.

\section{References}

[1] European patent EP 0704867 B1. 1999.

[2] Lode Vandenbossche, Sigrid Jacobs, François Henrotte, Kay Hameyer, «Impact of cut edges on magnetization curves and iron losses in e-machines for automotive traction», EVS-25 Shenzhen, China. The 25th World Battery, Hybrid and Fuel Cell Electric Vehicle Symposium \& Exhibition. Nov. 5-9, 2010.

[3] Erik Lamprecht, Martin Hömme, Thomas Albrecht «Investigations of Eddy Current Losses in Laminated Cores Due to the Impact of Various Stacking Processes», Daimler AG, 70546 Stuttgart, Germany.

[4] E. Obame Ndong, O. Gallot-Lavallée, and F. F. A itken, "Analytical heat transfer modeling of a new radiation calorimeter", Thermochim. Acta, vol. 633, pp. 56-68, Jun. 2016.

[5] Olivier Gallot-Lavallée, Frederic Aitken, and Elysée Obame, "Système calorimétrique et procédé pour mesurer les pertes de puissance dans un composant électrique,” Patent FR N¹055474 2010-07-13, 2010.

[6] Elysée OBAME NDONG « Développement d'un dispositif de calorimétrie par rayonnement thermique : application à la mesure des pertes dans les composants électriques». PhD, Univ. Grenoble.10 Septembre 2010

[7] Hakim DHAHBI «Caractérisation et modélisation de matériaux magnétiques pour capteurs de courant ». PhD, Communauté Univ. Grenoble Alpes. 09 April 2018. Chap 2,p.41-p.48.

[8] Thierry Gautreau « Estimation des pertes fer dans les machines electriques. modele d'hysteresis loss surface et application aux machines synchrones a aimants». PhD, Communauté Univ. Grenoble Alpes. 2005.

[9] Afef Kedous-Lebouc «Iron Loss calculation and analysis in electrical machines». Electrotechnica \& electronica Magazine, ISSN 0861-4717, pp. 3 - 6.10, 11-12/2008.

[10] International standards 60404-2 @ IEC:1996+A1:2008. 